\title{
Research on Cost Control of Construction Project Based on the Theory of Lean Construction and BIM: Case Study
}

\author{
Ye Wen*
}

College of Architecture Engineering, Guangzhou Panyu Polytechnic, Guangzhou, 511483, China

\begin{abstract}
Lean construction is a new type of management mode of construction project, which is especially suitable for those complex, changeable and speedy construction projects. Besides, building information model (BIM) is "computable digital information" created and utilized during the design and construction of buildings. This paper takes construction project as the object and combines BIM technology with the theory of lean construction. Both of them will play a collective role in cost control of construction project. A case study is made to illustrate that to the construction projects, the lean construction and BIM technology can control their cost effectively.
\end{abstract}

Keywords: BIM technology, Construction project, Cost control, Lean construction.

\section{INTRODUCTION}

The concept of lean construction was initially put forward by a Finland professor, Lauri Koskela (1993) based on National Construction and management Conference. He deemed that construction industry should learn from and take advantage of the basic principles, technology and means of lean manufacturing, adopt a new product theory, improve production efficiency of the construction process by eliminating waste and non-value-added activities and thus enhance the overall competitiveness of enterprises. And he believed that this introduction can make substantial progress in the construction industry in these years [1]. BIM technology is a kind of information technology used for the establishment and management of construction project information; meanwhile, it can integrate multiple building information databases, and realize modeling and parameterization of the entire construction project [2]. However, that BIM was treated as a process to explore the interaction between it and lean construction principles, was not a research focus until recently. Hamdi, Olfa and Leite, Fernanda IGLC (2012) believed that in building information modeling process, lean thinking had been used alone as a key method for the overall construction project to improve its models. And the combination of BIM technology and lean construction has been further validated in many cases of projects [3]. Bhargav A. et al., (2009) based on key technologies of lean construction and the core functions of BIM, created the coupling matrix of BIM technology and lean construction and concluded that BIM can contribute to the implementation of lean construction with high efficiency and reduce waste during project construction process and promote continuous improvement [4]. Yong-woo Kim et al., (2011) through case studies, considered that Lean Construction and BIM are the influencing factors of the overall delivery of the project. There is a link

*Address correspondence to this author at the College of Architecture Engineering, Guangzhou Panyu Polytechnic, Guangzhou, 511483, China;

Tel: 86-020-84744773; Fax: 86-020-84744773;

E-mail: yewen_py@163.com between the two and they can enhance each other and make the construction project team more integrated and collaborative [5].

Chinese scholars also affirmed the role collectively played by BIM technology and lean construction in construction projects. For example, Xu et al., (2012) thought that only based on the BIM application platform, can the concurrent engineering, pull production, value engineering, team work and other technologies and concepts of lean construction system be carried out substantially [6]. Accordingly, the progress of the project, its cost, quality and objectives can be realized; meanwhile, under the guidance of the lean construction system, the application environment of BIM is optimized constantly and a win-win result is realized. Each function of BIM supports several lean principles and a single lean principle can guide the application of several BIM technologies. However, only by repeatedly exploration and discoveries in practices, can we give full play to the comprehensive benefits of lean construction and BIM technology and bring maximum values to the projects [7].

In recent years, with the vigorous development of China's construction industry, the construction projects increases with each passing year, and the project cost increases sharply accordingly. Therefore, how to reasonably control costs, shorten the construction period and reduce waste and simultaneously ensure the quality of construction and building products so as to meet the growing consumer demand to the greatest extent has become an issue of construction which the contracting companies must face and solve. Lean construction and BIM is an emerging construction management technology. And when they work together, they can reduce construction costs and improve labor productivity, and thus create the greatest value [8-10]. They are strategic models and supporting systems in the reformative development of construction industry later and their application will bring great effects to the construction industry. In this paper, the lean construction theory and lean cost control theory and methods are put into reasonable application to control the 
actual cost of construction projects. Then, with the help of BIM technology platform, an in-depth discussion and analysis of the lean cost control methods in the project is made. Next, a systematic structure of cost control that is based on the lean construction theory and BIM technology is established. By doing so, the paper aims to provide references for the construction projects to maximize the value and minimize the waste, control and reduce the cost of construction project.

\section{RESEARCH METHODOLOGY}

This paper adopts the case analysis method. Firstly, the paper introduces the collective role of lean construction theory and BIM technology in improving the construction drawings and construction schemes so that the problems in constructions can be discovered in advance. Secondly, the combination of the two can inspect the interior support, set aside holes beforehand and manage and control the progress so as to ensure the quality, safety and duration of the project. Thus realizing the cost control of the construction project.

The case used in this paper is from the J2-5 project of Pearl River New City, which is located in the juncture of Hua cheng dadao Revenue and Xiancunlu Street in there. The project is positioned to be a CBD which integrates catering, banquets, high-end office buildings and supporting facilities into one. The project covers a total area of $7,470 \mathrm{~m}^{2}$, with a total construction area of $149,689.4 \mathrm{~m}^{2}$. Out of it, the ground floor area is $123,619.0 \mathrm{~m}^{2}$, and underground construction area is $26,070.4 \mathrm{~m}^{2}$. In structural style, it is a framecore tube structure. On the ground, there are 53 floors; and underground, there are four floors. The total height of the building is $252.10 \mathrm{~m}$. Besides, the basement is underground garage; the 1-5 layers are used for dining building, banquet hall and other ancillary facilities; 6-53 layers are used for office buildings and ancillary facilities (Fig. 1). The project has a large amount of construction volume and a tight time schedule. Besides, the available construction site is extremely narrow, and it is rather difficult to conduct the planar organization and management. Therefore, at the earlier stages of the project, the lean concept and theoretical methods, together with the BIM technology were introduced. Lean theory and BIM technology were combined to work jointly on the cost control of the construction project.

\section{THE CASE STUDY}

\subsection{Cost Control Analysis of Construction Project Based on Lean Construction Theory}

\subsubsection{Combination of Project Value Stream Management and BIM Technology vs. Cost Control}

First of all, value flow control is used in this paper. That is, unnecessary costs arising from the non-value-added activities during construction process are placed under control. And the value flow of the product is the very place where values and costs occur; furthermore, it is a place to identify and eliminate waste and control costs. The construction company puts the value flow management in the first place, because it meets the needs of the Lean Enterprise in costs control and it is the deciding factor of the enterprise's competiveness and success.

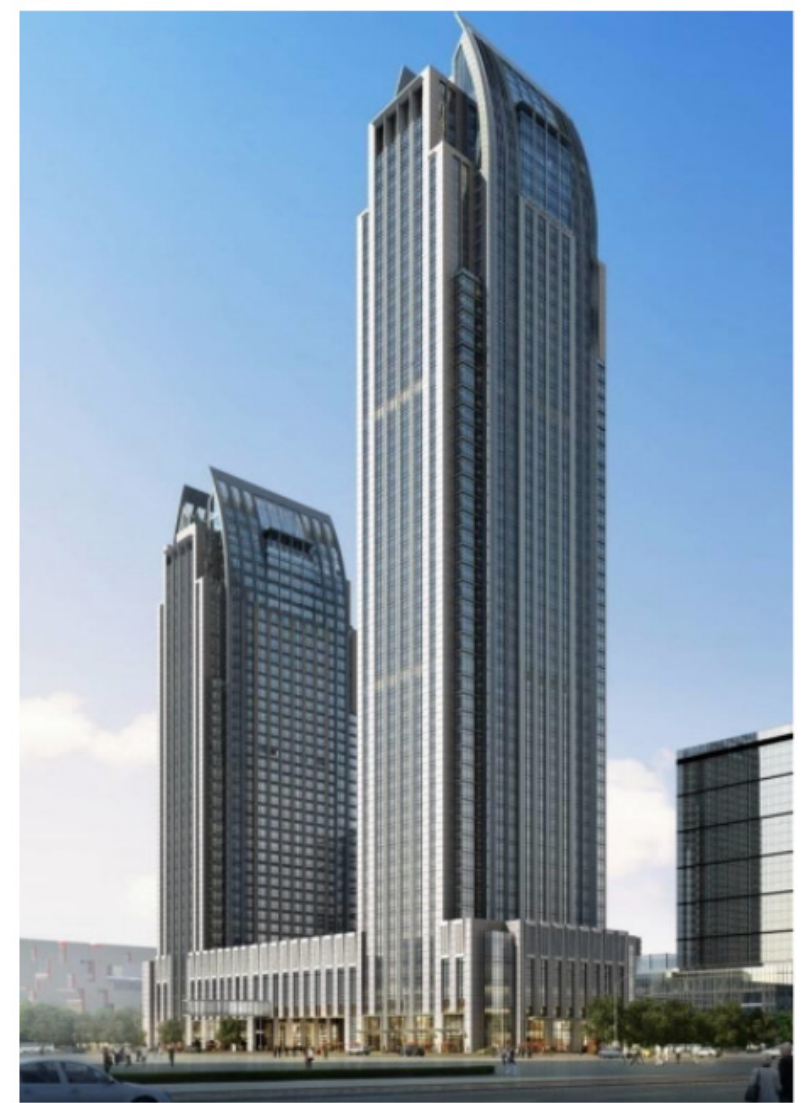

Fig. (1). Project Design Sketch.

Firstly, before construction, the construction enterprises should make the construction and production value flow mapping and accurately analyze the construction and production flow. Accordingly, the construction and production flow can be optimized. In essence, this aims to eliminate the nonvalue-added activities through process analysis, process design and process disparities control and other measures. Besides, the BIM technology is also used. At the stage of design, BIM technology is used to assess and monitor, to eliminate design errors and collisions and it also avoids the redundant designs in later stages, reduces design changes and a lot of reworks. Secondly, the construction company has placed a very good control of the budget costs in product development and design phase. The design phase determines the $70 \%$ to $80 \%$ of the product costs and in the effect of cost control, the development stage will play a bigger role in cost control and the other stages accounts only for $30 \%$ or so.

The construction company elaborates the cost planning of the project through the interactive action of lean construction theory and BIM technology, so to control most of the costs by the lowest development costs. Thus, it ensures that the product design is rational and advanced. Led by the project's BIM team, by virtue of BIM visualization functions, the owners, designer and contractors can find from multiple angles and then eliminate design errors of all kinds to reduce the variables in construction process. Besides, in the earlier planning and design, the project department uses the target cost management method, assigns clear tasks to and establishes clear working objectives to each constructor. Meanwhile, the project's target cost is subdivided layer by layer so 
as to be assumed by each staff in each department, to control the cost of construction project and reduce the non-planned costs.

The project's value flow management based on the lean construction theory mainly combines the following two technologies of BIM:

\section{(a) Interior Support Collision Detection Technology}

In this project, the time schedule for the basement is very tight. The project department therefore decided that, when the progress of main structure of the construction is made to \pm 0 , the pit support will be dismantled. In light of the special circumstances where the interior support is dismantled later, it is needed to position the basement structure and the Collision Point of Conflict in advance so as to determine the construction program and make organization in advance. Therefore, constructors can ensure the smooth implementation of the on-site construction, reduce rework and secondary construction and guarantee the time limit of the project.

Through on-site investigation, a BIM model is established based on the construction drawings. Then, BIM collision detection and visualization techniques are used to conduct collision detection to the basement structures and interior support (Fig. 2). As a result, a total of 72 collisions points are detected. Out of them, seven collision points can be reserved for treatment, 33 collision points need to be removed mechanically (Fig. 3), and 32 collision points can be resolved by drawings optimization. Through beforehand coordination and organization, a total duration of 14 days is saved, which saves a project expenditure of about RMB 439,000 (1US\$=6.129 yuan in 2014).



Fig. (2). Interior Support Collision Detection Model.

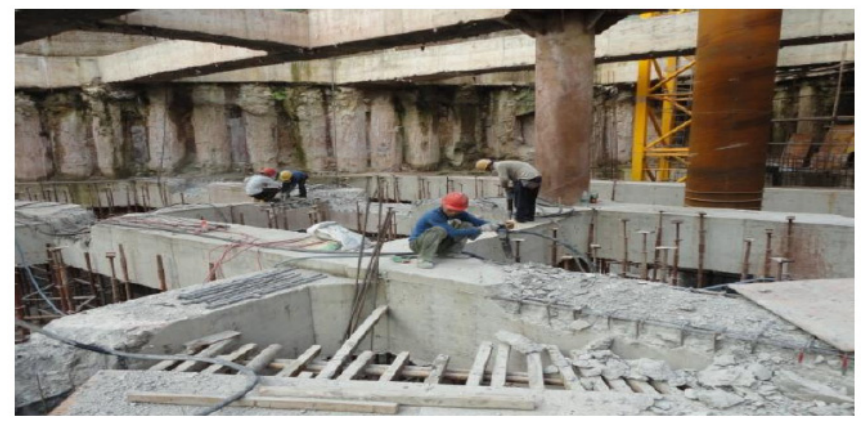

Fig. (3). Collision Points Removal Beforehand.

\section{(b) Pipeline Integration and Holes Reservation Technology}

During the basement construction of the project, collision detection is made for the secondary structures of the basement and its pipelines by means of BIM collision detection and visualization technology. A total of 549 collision points have been detected. By optimizing the pipeline arrangement (Fig. 4), the positions and sizes of the reserved holes are clarified. The volume of the reserved holes in pipelines of the basement walls is $10.6 \mathrm{~m}^{3}$, and a construction cost of RMB 18,020 is saved and the material waste caused by secondary cutting is avoided and civilized construction is executed.

\subsubsection{Project Supply Chain Management and BIM Tech- nology vs. Cost Control}

During the supply chain management process, the project construction enterprise (China Construction Eighth Engineering Division Co., Ltd) uses the BIM platform and does a good job in logistics management via efficient information management. Thereby, all parties in the supply chain can make a reasonable arrangement for their work activities and control costs of construction projects in accordance with the real-time progress and dynamic situations of the construction project updated by BIM team.

The construction enterprise adopts the pull-based lean production principles to supply raw materials which include the construction site layout where materials are stocked and shipments of large-scale materials. And by the integration of the corresponding database established by the BIM group for the project and supply chain database of the materials and equipment suppliers, constructors can more accurately ensure the quality and quantity of material supply and the timely delivery of the equipment to avoid the rework or delay of the construction project resulting from untimely supply of materials and equipment, or improper equipment type.

During the construction process, the construction company establishes a standard material \& supply file, follows the standardization management principle of lean construction and takes advantages of the real-time communication function of BIM technology in products and processes. Accordingly, the constructors have rules and regulations to follow; and the management administers can make files conveniently, thereby saving costs generated by human resources and materials. Besides, BIM team utilizes its platform to make a dynamic tracking of the inventory of the materials and goods, records detailed contents such as their delivery, loss, production, recycling and returns to the warehouse, provides quick feedback on the status quo of onsite goods and materials to project database. Thereafter, such information is given to each department on the supply chain so as to command the goods and materials flow of the whole supply chain, control risks and uncertainties, as well as the purchasing costs and inventory costs.

In addition to the project supply chain management, the "zero" storage technology of the BIM technology is combined to control the extra costs generated by the supply chain effectively. Besides, the construction site of the project is extremely narrow and only the north side can provide the construction site for materials storage, processing and crane transportation, which covers an area of about $427.2 \mathrm{~m}^{2}$, 


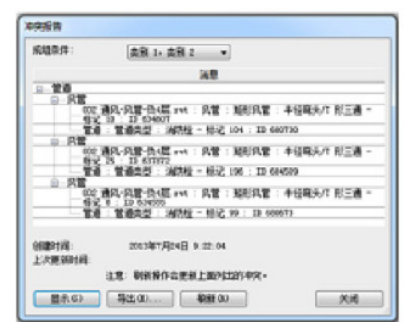

Detect pipeline collision
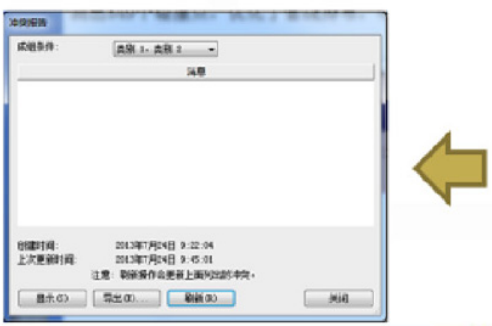

Redetect and eliminate the collision

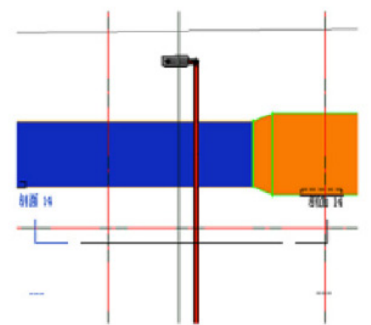

Show the collision position

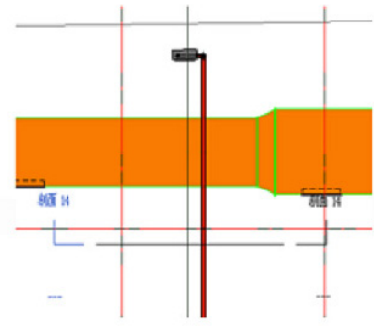

Switch to the section again

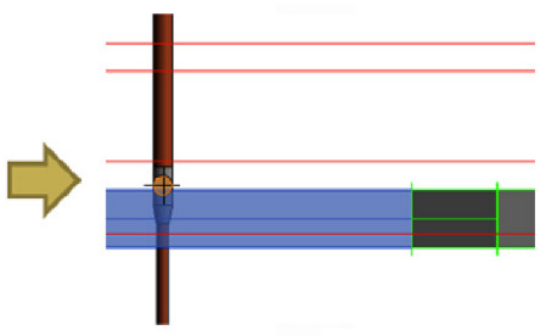

Switch to the section

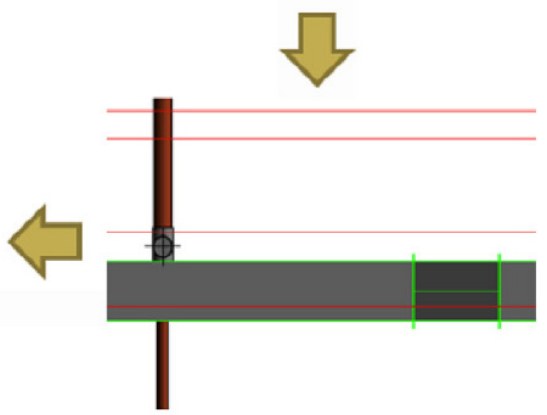

Adjust pipeline position

Fig. (4). Pipeline Arrangement Optimization.

merely accosting for $5.72 \%$ (Fig. 5) of the total areas covered by the project. Consequently, this not only affects the storage and processing of the onsite materials but also seriously affect the living and working conditions of the staffs on the construction site.

BIM technology is used to deepen the construction drawings and construction program to find out in advance and then solve the problems in the construction. Take full advantage of off-site professional processing conditions and resources, and transfer the templates, steel, masonry and other professional projects which are traditionally processed within the site to the places outside for off-site processing (Fig. 6). And according to materials delivery scheme that is made on the basis of the logistics management concept, (logistics plan's preparation process is shown in Fig. 7), ensure that the materials can be orderly and timely delivered to each construction sites. As a result, there will be no need to set professional storage yard in the construction site, no need to make onsite processing, and no need to make secondary delivery. By doing so, the adverse impacts caused by insufficient space can be avoided and change disadvantageous factors into advantageous factors to get a positive and effective command of the realization of each objective.

\subsubsection{Combination of Last Planner System and BIM Technology vs. Cost Control}

The construction company practices last planner system in the construction process and with the help of BIM team, it builds a stable and controllable construction project workflow. During the construction process, the project department makes the constructors to manage the actual specification by themselves, vigorously give play to initiatives and enthusiasm of the grassroots staffs or teams play. Meanwhile, BIM 4D tools are used to simulate the construc- tion steps and show them by animations. BIM team provides various departments with visualized construction process to reduce uncertainty. Furthermore, high-level planners can more easily realize or control more constraints to optimize the construction process and ensure the stability of the workflow and control the uncertain costs.

Due to the complex, ever-changing and dynamic features of the construction project, the project department should make a dynamic plan so as to able to track the progress of the project timely, and weekly call the constructors for a meeting to make summarizations and make the next-week plan timely. Meanwhile, the plan should be effectively carried by each constructor, to keep the construction schedule in a controllable range and to avoid uncertainties in the construction process, thus achieving the purpose of cost control. Assess and measure the project weekly by calculating the project plan completion rate. Use the target cost management method, summarize the completed tasks, analyze the unfinished tasks and find out the reasons to facilitate the future work. The project must keep a five-week forward-looking plan, and make a systematic arrangement in weekly onsite meeting to ensure the activities in the forward-looking plan to be implemented by each headman. Specifically speaking, this includes 7 aspects such as information management, material supply, human resource allocation, supply of equipment, completion of previous work, entry into construction site and external conditions to keep the continuity of work flow unimpeded, thus effectively controlling the occurrence of uncertain costs. Meanwhile, to maintain the stability of the workflow, the project utilizes the last planer system, together with the BIM technology, to control the progress so that the uncertain costs are well controlled.

As the project schedule is very tight, according to the actual situation of the project, a fine ergonomics research is 


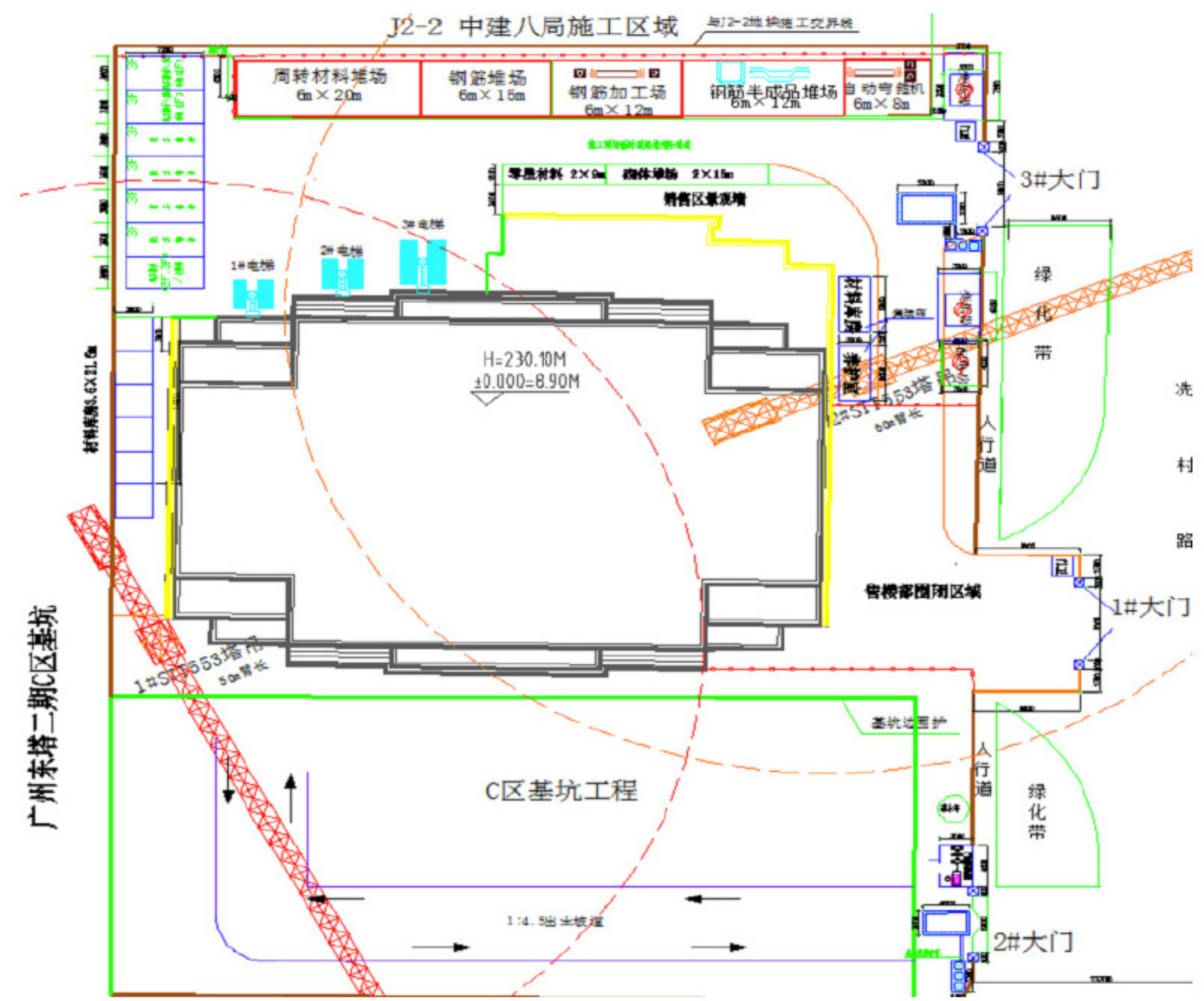

Fig. (5). Site Planar Layout Mapping.

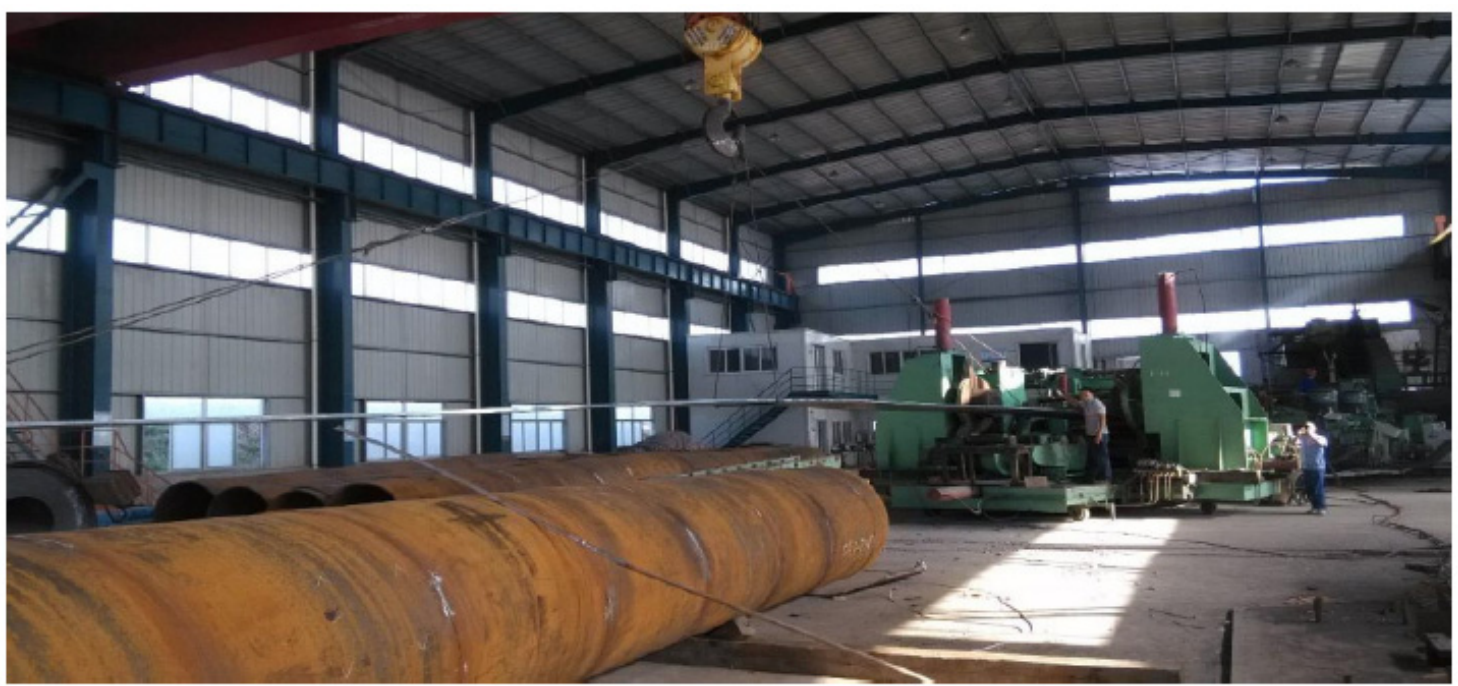

Fig. (6). Off-site Professional Processing.

conducted on the key trades. Later in accordance with the schedule requirements and the data obtained from the ergonomics research, a digit-based management \& control scheme is made on the basis of the BIM visualization analysis and automatic calculation of work amount. Therefore, a clear allocation of resources and the duration required for each job is determined. In addition, reminder software is used to provide warning for each step, as well as the before- hand organization of BIM and its process guidance. Accordingly, the smooth implementation of each work process and the time limit for the project can be guaranteed.

\subsection{Effects Analysis}

With the introduction of lean construction theory and the support of the BIM technology, after performing the above steps, favorable improvement has been made in the duration 


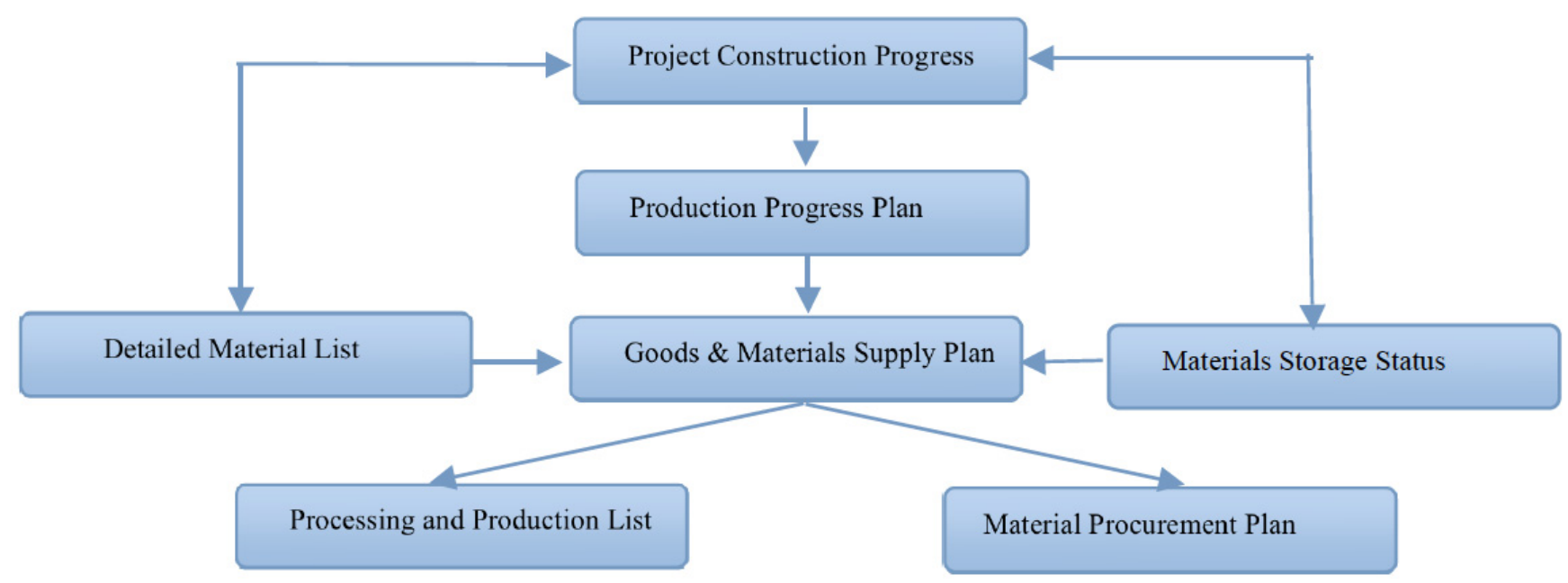

Fig. (7). Logistics Plan Preparation Process.

of construction project, its progress, project quality and safety incidents and resource utilization etc. In the basement construction phase, the project starts to use the BIM technology. Specifically, BIM technologies are applied into interior support detection, pipeline integration and holes reservation, beforehand deepening and progress management and control. This not only ensures the smooth implementation of the onsite construction but also saves related costs, creates economic benefits totaling RMB 1.759 million. The economic benefits are calculated as follows:

(a) Interior support detection: The collision points are detected via BIM model and treated accordingly in advance. Through coordination and organization in advance, save a total of 14 days, direct saves a project expenditure of about RMB 439,000.

(b) Hole reservations: BIM collision detection and visualization technology are used to optimize the pipeline arrangement and clarify the locations and sizes of the reserved holes, which directly saves a construction cost totaling RMB 18,000 .

(c) Beforehand deepening and progress management and control.

By combining BIM technology and aluminum die system, each standard layer can save one day, each layer a project cost of about RMB 31,000. There are a total of 42 standard floor layers. Therefore, 42 days and RMB 1.302 million can be saved.

The specific effects of the project are listed as below:

(a) In the project construction, the use of the site is improved and waste is reduced and moreover, the space for storing onsite materials is saved, which leads to a significant reduction in management costs. Construction project improves its productivity and production efficiency, and the non-value-added operations are reduced. Meanwhile, the rework, downtime and work delay incidents are decreased, thus controlling the project cost effectively.

(b) Judging from the statistical data, project completion rate has been significantly improved, from $30 \%$ to around $85 \%$ per week. At the same time, employees also receive higher incentives. The duration of the project is significantly shortened; a quicker progress is gradually made. Thereby, the construction company is able to finish the construction tasks with a high quality efficiently.

(c) Enhance cooperation in all sectors of the supply chain; identify and eliminate waste in the supply chain and avoid the occurrence of some of the costs, thereby improving the supply chain efficiency and reducing the purchasing and inventory costs. Enterprise's logistics supply plan is improved, thus effectively reducing the inventory and emergency procurement demands etc.

(d) The incidents rate of the project is reduced remarkably.

\section{CONCLUSION}

During the process of rapid development of the construction industry, construction enterprises are looking for new ways to effectively control the costs of construction projects to obtain greater profit margins. The initial success of lean construction theory in the construction industry is undoubtedly a dose of cardiac stimulant for corporate management, which is a good lesson for the cost control of the construction project. The introduction of BIM technology, enhance the cost control of construction project by lean construction theory. Through actual case, the paper illustrates that the introduction of lean construction theory and BIM technology into the construction projects can effectively improve the efficiency of construction project, reduce the non-valueadded activities, control costs efficiently, and ultimately maximize the value of the project and meet customer needs. Meanwhile, the case provides a practical reference for cost control of construction project by introduction and application of the lean construction theory and BIM technologies.

\section{CONFLICT OF INTEREST}

The authors confirm that this article content has no conflict of interest.

\section{ACKNOWLEDGEMENTS}

Declared none. 


\section{REFERENCES}

[1] L. Koskela, "Application of New Production Philosophy to Construction", Technical report 72. CIFE, Stanford University, pp. 75, 1992.

[2] D. Smith, "An introduction to building information modeling (BIM)", Journal of Building Information Modeling, vol. 1, pp. 1214, 2007.

[3] O. Hamdi, and L. Fernanda, "BIM and lean interactions from the BIM capability maturity model perspective: A case study", In: Proceedings for the $20^{\text {th }}$ Annual Conference of the International Group for Lean Construction, 2012.

[4] A. Bhargav, R. S. Dave, and L. Koskela, "Analysis framework for the interaction between lean construction and building information modeling", In: Proceedings for the $17^{\text {th }}$ Annual Conference of the International Group for Lean Construction, vol. 12, pp. 221-231, 2009.

[5] Y.W. Kim, and C. S. Dossick, "What makes the delivery of a project integrated? A case study of Children's Hospital, Bellevue,
WA", Lean Construction Journal (Lean and Integrated Project Delivery Special issue), vol. 1, pp. 53-6, 2011.

[6] Q.S. Xu, Z.M. Su, and X.H. Wang, "Integration to achieve the key technologies of the lean construction based on the BIM and advantage analysis", Science and Technology Management Research, vol. 7, pp. 104-110, 2012.

[7] B. Zhao, B.S. Niu, and Y.Q. Wang, "The Interactive Application of Lean Construction and BIM Technology in Construction", Journal of Engineering Management, vol. 25, pp. 482-487, 2011 (in Chinese).

[8] R. Sacks, L. Koskela, and B, Dave, "Interaction of lean and building information modelingin construction", Construction Engineering and Management, vol. 9, pp. 973-978, 2010.

[9] L. Koskel, "Application of the new production philosophy to construction" CA: Center for Integrated Facility Engineering, Department of Civil Engineering, Stanford University, 1992

[10] L. Koskela, and R. Owen, "Interaction of lean and building information modeling in construction", Construction Engineering And Management, vol. 9, pp. 968-980, 2010.

(C) Ye Wen; Licensee Bentham Open.

This is an open access article licensed under the terms of the Creative Commons Attribution Non-Commercial License (http://creativecommons.org/licenses/by-nc/3.0/) which permits unrestricted, non-commercial use, distribution and reproduction in any medium, provided the work is properly cited. 